\title{
Perceived Parenting Styles and Mental Health: The Multiple Mediation Effect of Perfectionism and Altruistic Behavior
}

\section{Linlin Feng \\ Lelin Zhang \\ Hao Zhong}

School of Marxism, Shandong University of Technology, Zibo, 255000, People's Republic of China
Correspondence: Linlin Feng

School of Marxism, Shandong University of Technology, No. 266 West Xincun

Road, Zibo, 255000, People's Republic of China

Email fenglinlin@sdut.edu.cn
Background: According to the ecological systems theory, the microsystems are important during the development process because they have direct effects on immediate and proximal factors that shape human development. The theory identifies the family as a microsystem that has profound influence on development since it is the immediate environment in which individuals live. This study explored the multiple mediation effect of perfectionism and altruistic behavior on the association between perceived parenting styles and mental health. Methods: In this cross-sectional study, convenience cluster sampling was used, and the purpose was empirically examined by means of an online questionnaire survey. This study adopted the Demographic Questionnaire, short-form Egna Minnen Beträffande Uppfostran, Chinese Frost Multidimensional Perfectionism Scale, Self-Reported Altruism Scale, and General Health Questionnaire to conduct measurements in 525 university students.

Results: The results of the correlation analysis revealed that perceived parenting styles were significantly correlated to perfectionism, altruistic behavior, and mental health. In addition, perfectionism and altruistic behavior were significantly correlated to mental health, while negative perfectionism was not correlated to altruistic behavior. The results of the structural equation model analysis indicated that parental rejection and emotional warmth had direct and significant effects on children's mental health. Positive perfectionism and altruistic behavior not only played partial mediating roles between parental emotional warmth and children's mental health but also exerted a chain multiple mediation effect. Altruistic behavior played a partial mediating role between positive perfectionism and mental health. Conclusion: Therefore, parents should practice positive parenting styles such as parental emotional warmth toward their children to ensure that positive perfectionism and altruistic behavioral tendency improve mental health.

Keywords: perceived parenting styles, perfectionism, altruistic behavior, mental health, multiple mediation effect

\section{Introduction}

Mental health is a state of well-being in which individuals realize their own potential and abilities to cope with the normal pressures in life and can study and work with quality, thereby generating a positive effect on the surrounding environment. ${ }^{1}$ Mental health status is affected by various factors. The ecological systems theory proposed by Bronfenbrenner states that family, as a microsystem, has the most direct effect on individuals. ${ }^{2}$ Perceived parenting styles can affect the mental development of individuals in this system, which is closely related to their mental health status. ${ }^{3}$ The behavioral patterns and tendencies of parents in raising 
children constituted their parenting styles; ${ }^{4}$ these parenting styles were interactive and consistent in various situations. ${ }^{5}$ Studies have discovered that children who were often rejected by their parents had more unstable emotions, higher reverse psychology abilities, and were prone to hostile aggressive behaviors than children who were often accepted by their parents, who demonstrated more frequent prosocial behaviors, specifically expressed as compassion, wide-ranging hobbies, and a helpful nature. ${ }^{6,7}$ In addition, studies have identified that parenting styles were correlated with children's mental health. Positive parenting styles were conducive to the formation of a healthy mental status among the children. Children with parents who do not understand and accept them are more prone to mental illnesses such as neurosis and mood disorders. ${ }^{8,9}$ Therefore, the effect of parenting styles on mental health and the influence mechanisms should be explored. On the basis of relevant studies, ${ }^{6,10}$ this study further explored the role of perfectionism and altruistic behavior as mediators of the association between parenting styles and children's mental health.

Perfectionism among individuals refers to setting unrealistically high standards for themselves and using these standards to measure self-worth. ${ }^{10}$ Most researchers have claimed that perfectionism may be positive or negative. $^{11,12}$ The present study adopted the Chinese Frost Multidimensional Perfectionism Scale compiled by $\mathrm{Zi}$ and Zhou because it is more suitable for use in the Chinese cultural environment. ${ }^{11}$ Studies have asserted that individuals' perfectionism stemmed from early experiences and parental influence. ${ }^{13,14}$ In addition, Zhou noted that the formation of individuals' perfectionism was closely related to the parenting styles experienced by the individuals. $^{12}$ That is, parenting styles of the father or mother can affect the generation and development of children's perfectionism. Positive parenting styles can promote the formation of positive perfectionism, whereas a harsh disciplinary parenting style increases the tendency of children to develop negative perfectionism. Moreover, perfectionism is a crucial factor affecting mental health. Studies have shown that an individual's positive perfectionism tendency was positively correlated with positive mental health indicators (eg, self-esteem, positive emotions, and subjective well-being). By contrast, an individual's negative perfectionism was strongly correlated with negative mental health indicators, such as anxiety, depression, and compulsion, and significantly and positively correlated with negative emotions. ${ }^{15-17}$ Specifically, positive perfectionism is a kind of benign psychological characteristic that focuses on cleanliness and proper organization, and feedback is a feature of the ability to actively regulate mental health. By contrast, negative perfectionism is generally the cause of certain mental illnesses. ${ }^{11}$ Therefore, Hypothesis 1 was proposed: Positive parenting styles can lead to stronger positive perfectionism and weaker negative perfectionism in individuals, thus leading to better mental health status. That is, the mediating effect of perfectionism can help predict the effect of parenting styles on children's mental health.

Altruistic behavior refers to behavior that benefits other individuals at the cost of the individual. ${ }^{18}$ In general, altruistic behavior was considered the highest level of prosocial behavior. According to the social cognitive theory, behaviors exhibited by an individual are the result of his/her observation, learning, and imitation. ${ }^{19}$ Because parents have the most contact with children in their early stages of child development, parents have a direct influence on their children's altruistic behavior. ${ }^{20}$ In particular, children who received care and a warm upbringing from their parents were more likely to develop positive behaviors. ${ }^{21}$ Relevant studies have shown that positive parenting styles were conducive to the development of positive peer relationships and excellent social adaptability. ${ }^{22,23}$ Specifically, children were influenced by the parenting process. Parents' altruistic behaviors in daily life are imitated and learned by children to a certain extent, which strengthens the interpersonal communication skills among the children. For example, when children encounter situations similar to their parents' experiences, they tend to make choices similar to those of their parents. Kou et al noted that the development of altruistic behaviors is usually a process of external presentation of internalized values. ${ }^{24}$ Parents' positive parenting behaviors promote altruistic tendencies in their children. In addition, the parents' altruistic behaviors confer a sense of value to their children, thereby enabling the children to continually internalize altruistic behaviors into natural behaviors in their daily lives to develop a stable personality. Berkowitz proved that the altruistic behaviors of people are attributed to their inner responsibility. ${ }^{25}$ The concept of altruistic value is internalized into the consciousness and manifested as behavior, which not only enables individuals to adapt to their own life but also makes it easier for them to integrate into the community. In addition, Adler claimed that altruistic behavior had a psychological healing effect, ${ }^{26}$ that is, individuals were prone to identify their self-worth and stimulate emotional spillovers when displaying altruistic behaviors, 
thereby generating a certain positive effect on mental health. ${ }^{27}$ Therefore, Hypothesis 2 was proposed: Positive parenting styles can promote altruistic behavior and high mental health status in children, that is, altruistic behavior plays a mediating role in the association between parenting styles and mental health.

From the perspective of social desirability, perfectionism and altruistic behavior were both guided by social expectations and were strongly correlated with each other. Zhang et al discovered that perfectionism in adolescents had a predictive effect on prosocial tendency, ${ }^{28}$ and correlation between the two was influenced by motivation. ${ }^{29}$ Moreover, children's physical and psychological factors undergo tremendous changes with age. Although these changes are affected by the parenting styles experienced by the children, children are eager to form an independent personality and explore their personalities through social interaction. Furthermore, children influenced by rational thinking portray their perceived perfect image through organized thinking when communicating with parents and teachers. These children were more likely to exhibit altruistic behaviors, which in turn enhanced their self-confidence and benefitted their mental health. Negative perfectionism mostly pointed to negative emotions. Individuals who were strongly affected by negative perfectionism pursued the ultimate high standards when dealing with problems and forced themselves to achieve the high expectations of their parents. As a result, they often experienced self-denial and selftorture. Difficulty in cooperation and communication with others was not conducive to the generation of altruistic behaviors in individuals and had a negative effect on the healthy growth of individuals. Therefore, a causal relationship may exist between parenting styles and mental health; that is, parenting styles may affect mental health through perfectionism and altruistic behavior. Accordingly, the study proposed Hypothesis 3: Perfectionism has a significant predictive effect on altruistic behavior, and perfectionism and altruistic behavior exert a significant chain multiple mediating effect on the association between parenting styles and mental health.

Nowadays, many Chinese university students face a special situation that they do not have siblings to interact with due to China's One-Child Policy. ${ }^{30}$ Previous researchers worried that these only child would be spoilt by their parents and become "little emperors". 30,31 Chen et al documented that significantly more self-centered and less cooperative individuals have been produced, and this has led to widespread concern within China about the social skills and mental health of these only child. ${ }^{30}$ Chinese university students' mental health and the influencing factors should be particularly paid attention to. Moreover, this study not only focused on positive parenting styles such as parental emotional warmth but also focused on negative parenting styles such as parental rejection and overprotection, aiming to investigate which parenting styles are beneficial to university students' behavioral tendency and mental health, and which parenting styles are detrimental. Western cultures are often characterized by individualism and personal agency, while Chinese culture is often characterized by interdependence and mutual connection. ${ }^{32}$ In Chinese cultural background, strong parental control was usually viewed as an expression of love, ${ }^{33}$ as a result, maybe parental overprotection in Chinese cultural background had less negative effects on children's mental health than in Western cultural backgrounds.

Furthermore, the relationship between parenting styles and university students' mental health has seldom been explored in university students whom with high levels of idealism and great amounts of energy. ${ }^{34}$ Individual's perception of parenting styles is not immutable. ${ }^{35}$ This study has great practical value because the parenting styles of university students are easy to be ignored, and the mental health of university students is of great concern in present-day China. University students are in an important stage of psychological development. They are facing a series of problems, such as living and studying independently without their parents, and it is easy to produce negative emotions. ${ }^{9}$ Therefore, it is of practical significance to explore the mental health of university students and its influencing factors.

According to the ecological systems theory, ${ }^{2}$ the microsystems are important during the development process because they have direct effects on immediate and proximal factors that shape human development. The theory identifies the family as a microsystem that has profound influence on development since it is the immediate environment in which individuals live. This study explored the chain multiple mediation effect of perfectionism and altruistic behavior on the association between perceived parenting styles and mental health.

\section{Materials and Methods Participants and Procedure}

In this cross-sectional study by means of an online questionnaire survey, convenience cluster sampling was used. The reason for collecting data online was being the 
COVID-19 pandemic. A power analysis was conducted using $\mathrm{G}^{*}$ Power $3.1^{36}$ in which the estimated effect size of $r=0.14, \alpha=0.05$ (two-tailed), and power $=0.80$. The result suggested a required sample size of $N=311$. Thus, we chose to examine the association of perceived parenting styles with mental health in a larger sample to increase sensitivity. A total of 550 university students were recruited at a university in eastern China, and 550 questionnaires were distributed. After invalid questionnaires were excluded because there were much missing data, a total of $525\left(N_{\text {men }}=198, N_{\text {women }}=327 ; M_{\text {age }}=20.18\right.$, $\left.S D_{\text {age }}=1.57\right)$ valid questionnaires remained, with a valid response rate of $95.45 \%$.

The study was carried out as follows: First, we communicated with the university students on the Internet. After obtaining their informed consent, we sent questionnaires online and they answered the online questionnaires. The data collection procedures lasted approximately 30 minutes. All these participants were willing to cooperate with this survey and can complete our questionnaires independently. The measures were administrated to the participants by two trained research assistants online. We did not send questionnaires to those who were not willing to cooperate with the investigation. Due to the missing data in the key study variables, we excluded 25 individuals and the final sample size was 525 .

The participants completed measures including the Demographic Questionnaire, the short-form Egna Minnen Beträffande Uppfostran, the Chinese Frost Multidimensional Perfectionism Scale, the Chinese version of the Self-Report Altruism Scale Distinguished by the Recipient, and the Chinese version of the 12-item General Health Questionnaire (total 110 items). The participants were informed that the measures included questions on their beliefs and experiences in daily life and were encouraged to respond to all the items accurately. Upon study completion, each participant received a bonus (CNY $6=$ US \$0.93) for compensation.

\section{Ethical Statements}

This study was conducted under the approval of the Institutional Review Board (IRB) at the University and was conducted in accordance with the Declaration of Helsinki. The participants were made aware of the voluntary and confidential nature of this study. They were fully informed of the research before participation, such as purpose and content. Written consent was obtained prior to the administration. All participants were over 18 years old, and there were no minors involved. This study caused no harm to participants' physical and mental health, and the results of this study were maintained confidentially.

\section{Measures}

\section{Demographic Characteristics}

The participants provided demographic characteristics information including their gender and age, the number of children in the home, the home location, and paternal/ maternal education and current occupation.

\section{Perceived Parenting Styles}

The short-form Egna Minnen Beträffande Uppfostran revised by Jiang et al was used to measure perceived parenting styles, ${ }^{37}$ which includes 42 items divided into three aspects - parental rejection (12 items; eg, "Father/ mother often scolds me without any reason."), emotional warmth (14 items; eg, "Father/mother praises me."), and overprotection (16 items; eg, "I hope my father/mother does not excessively worry about what I am doing."). The items in the questionnaire were rated on a four-point scale, with higher scores (response scores were averaged to create their composite scores for data analysis) indicating higher parental rejection/emotional warmth/overprotection levels. This study examined the influence of parents' overall parenting styles on university students' mental health. Therefore, father and mother dimensions were adopted from related studies and combined with the parent dimension. ${ }^{38,39}$ The overall internal consistency reliability of the questionnaire was 0.92 , and the internal consistency reliabilities of parental rejection, emotional warmth, and overprotection were $0.95,0.94$, and 0.87 , respectively.

\section{Perfectionism}

The Frost Multidimensional Perfectionism Scale revised by $\mathrm{Zi}$ and Zhou was employed to measure the perfectionism tendency of the included university students. ${ }^{11}$ This scale includes 27 items divided into domains of organization (six items; eg, "Doing things in an organized manner is crucial to me."), personal standards (six items; eg, "I might become a second-class person if I do not set the highest standards for myself."), self-doubt (four items; eg, "I often feel that I am not doing things right even if I try to be careful."), parents' expectations (five items; eg, "My parents set high standards for me."), and worry about mistakes (six items; eg, "If I fail in school, I am 
a failure as a human being."). Among them, the organization aspect is related to positive perfectionism, while the others are related to negative perfectionism. A five-point scoring system was adopted to measure these aspects. Higher scores (response scores were averaged to create their composite scores for data analysis) indicated stronger perfectionism tendency of the individual. The overall internal consistency reliability of the questionnaire was 0.93 , and the internal consistency reliabilities of positive and negative perfectionism were 0.86 and 0.94 , respectively.

\section{Altruistic Behavior}

The Self-Reported Altruism Scale Distinguished by the Recipient was adopted to measure the altruistic behavior tendency of the included university students. ${ }^{34}$ This scale includes 21 items and has three domains - kin altruism to family members (seven items; eg, "I will support my family members when they need help."), reciprocal altruism to friends (seven items; eg, "I will listen to the distress and complaints of friends or acquaintances."), and pure altruism to strangers (seven items; eg, "I will help strangers put their luggage on the luggage rack in a train or car."). The items in this scale were scored on a five-point scale, with higher scores (response scores were averaged to create their composite scores for data analysis) denoting stronger tendency of an individual to be altruistic. The overall internal consistency reliability of the scale was 0.97 , and the internal consistency reliabilities of kin altruism, reciprocal altruism, and pure altruism were 0.94, 0.93, and 0.92 , respectively.

\section{Mental Health}

The 12-item General Health Questionnaire revised by Li and $\mathrm{Li}$ was used to measure the mental health of the included university students. ${ }^{40}$ The 12 items were divided into positive health (six items; eg, "Can you concentrate on doing your own work?") and negative health (six items; eg, "Do you experience insomnia due to worrying?") domains. The items were scored on a four-point scale, with higher scores (response scores were averaged to create their composite scores for data analysis) indicating more serious mental health problems in an individual. The overall internal consistency reliability of the questionnaire was 0.86 , and the internal consistency reliabilities of positive and negative health were 0.77 and 0.79 , respectively.

\section{Data Analysis}

Descriptive statistics and correlational analysis in this study were conducted with the statistical software IBM SPSS 19.0. Amos 23.0 was used to conduct path analysis and multiple group comparison with maximum likelihood estimation. Evaluations of Structural Equation Modeling were conventionally based on the following statistics: the comparative fit index (CFI), the Tucker-Lewis index (TLI), and the root-mean-square error of approximation (RMSEA). ${ }^{41,42}$ Moreover, the Bootstrap method was used to test the mediating effect, wherein repeated random sampling was used to collect $n$ samples $(n=5000)$ from the raw data to generate and save $n$ mediating effect values to form an approximate sampling distribution, and the mean path coefficient of the mediating effect was calculated. If the $95 \%$ confidence interval of these mean path coefficients did not include 0 , it indicated that the mediating effect was significant. ${ }^{43}$

\section{Common Method Bias Test}

This study used Harman's single-factor test. The results of the unrotated principal component factor analysis revealed 17 factors with an eigenvalue of $>1$. In addition, the first factor explained only $18.01 \%$ of the variance, which was less than the critical standard of $40 \%$, indicating no obvious common method bias in this study.

\section{Results}

\section{Demographic Information and Gender Differences in Perceived Parenting Styles, Perfectionism, Altruistic Behavior, and Mental Health}

Among the participants, 198 were men and 327 were women, aged between 17 and 25 years (mean age, 20.18; standard deviation, 1.57). Of the university students, $30.29 \%$ were only child. Of the university students, $28.95 \%$ came from city, and $71.05 \%$ of the university students came from countryside. Of the fathers, $13.90 \%$ and of the mothers, $10.48 \%$ had a college education. The remainder had either a high school education $(27.62 \%$ of fathers and $20.19 \%$ of mothers) or a middle school education $(39.05 \%$ of fathers and $36.95 \%$ of mothers) or less education $(19.43 \%$ of fathers and $32.38 \%$ of mothers). Of the fathers, $29.33 \%$ and of the mothers, $28.95 \%$ held a professional, managerial, or technical position (eg, teachers, doctors, civil officials). Of the fathers, $34.10 \%$ and of the mothers, $25.33 \%$ were employed 
at working-class jobs (eg, factory workers), and $36.57 \%$ of the fathers and $45.72 \%$ of the mothers were employed as temporary workers, farmers, or unemployed people. The detailed results are summarized in Table 1.

This study used gender as the independent variable; perceived parenting styles, perfectionism, altruistic behavior, and mental health as the dependent variables to investigate the gender differences for each variable. The results revealed that gender differences were significant in parental rejection and overprotection but was not significant in parental emotional warmth. Specifically, men perceived parental rejection and overprotection were significantly higher than women, while men's and women's perceived parental emotional warmth was not significant. In addition, there were also gender difference in negative perfectionism, specifically, men's negative perfectionism was significantly higher than women's. The detailed results are summarized in Table 2.

\section{Correlations Among Perceived Parenting} Styles, Perfectionism, Altruistic Behavior, and Mental Health

Descriptive statistics and correlation analysis were used to evaluate the correlation among perceived parenting styles, perfectionism, altruistic behavior, and mental health, and the results are presented in Table 3. The findings indicated that parental rejection was significantly and positively correlated with negative perfectionism and mental health; parental emotional warmth was significantly and positively correlated with positive perfectionism and altruistic behavior, and was significantly and negatively correlated with negative perfectionism and mental health; parental overprotection was significantly and positively correlated with positive and negative perfectionism. Moreover, positive perfectionism was significantly and positively correlated with altruistic behavior, but significantly and negatively correlated with mental health; negative perfectionism was significantly and positively correlated with mental health. Altruistic behavior was significantly and negatively correlated with mental health.

\section{Multiple Mediation Effect of Perfectionism and Altruistic Behavior Between Perceived Parenting Styles and Mental Health}

Negative perfectionism and altruistic behavior were not significantly correlated; the chain multiple mediating effect of negative perfectionism and altruistic behavior on the association between perceived parenting styles and mental health was not significant. Therefore, this study only examined the chain multiple mediation effect

Table I Demographic Information

\begin{tabular}{|c|c|c|c|c|c|c|}
\hline Variables & Frequency & Percent & Minimum & Maximum & $\mathbf{M}$ & SD \\
\hline Gender & & & I & 2 & 1.62 & 0.49 \\
\hline Men & 198 & $37.71 \%$ & & & & \\
\hline Women & 327 & $62.29 \%$ & & & & \\
\hline Only child & & & I & 2 & 1.70 & 0.46 \\
\hline Yes & 159 & $30.29 \%$ & & & & \\
\hline No & 366 & $69.71 \%$ & & & & \\
\hline Residence & & & I & 2 & 1.71 & 0.45 \\
\hline City & 152 & $28.95 \%$ & & & & \\
\hline Countryside & 373 & $71.05 \%$ & & & & \\
\hline Paternal/Maternal education & & & $1 / 1$ & $6 / 6$ & $3.35 / 3.05$ & $1.03 / 1.07$ \\
\hline College education & $73 / 55$ & $13.90 \% / 10.48 \%$ & & & & \\
\hline High school education & $145 / 106$ & $27.62 \% / 20.19 \%$ & & & & \\
\hline Middle school education & $205 / 194$ & $39.05 \% / 36.95 \%$ & & & & \\
\hline Less education & $102 / 170$ & $19.43 \% / 32.38 \%$ & & & & \\
\hline Paternal/Maternal occupation & & & $1 / 1$ & $5 / 5$ & $2.24 / 2.06$ & $1.37 / 1.27$ \\
\hline Professional, managerial, or technical position & $154 / 152$ & $29.33 \% / 28.95 \%$ & & & & \\
\hline Working class jobs & $179 / 133$ & $34.10 \% / 25.33 \%$ & & & & \\
\hline Temporary workers, farmers, or unemployed people & $192 / 240$ & $36.57 \% / 45.72 \%$ & & & & \\
\hline
\end{tabular}

Abbreviations: $M$, mean value; SD, standard deviation. 
Table 2 Gender Differences in the Key Study Variables

\begin{tabular}{|l|c|c|c|c|c|}
\hline \multirow{2}{*}{} & \multicolumn{2}{|c|}{ Men } & \multicolumn{2}{c|}{ Women } & \multirow{2}{*}{ t } \\
\cline { 2 - 5 } & M & SD & M & SD & \\
\hline Parental rejection & 1.68 & $0.7 \mathrm{I}$ & 1.52 & 0.63 & $2.6 \mathrm{I}^{* *}$ \\
Parental emotional warmth & 2.85 & 0.68 & $2.9 \mathrm{I}$ & $0.6 \mathrm{I}$ & -0.94 \\
Parental overprotection & 2.18 & 0.54 & 2.04 & $0.5 \mathrm{I}$ & $3.00^{* *}$ \\
Positive perfectionism & 3.79 & 0.68 & 3.83 & 0.65 & -0.73 \\
Negative perfectionism & 3.35 & 0.68 & 3.12 & 0.75 & $3.55^{* * *}$ \\
Altruistic behavior & 4.06 & 0.77 & 4.08 & 0.68 & -0.29 \\
Mental health & 1.54 & 0.44 & 1.56 & 0.39 & $-0.4 \mathrm{I}$ \\
\hline
\end{tabular}

Notes: $* * p<0.01$, ***p $<0.001$.

Abbreviations: $M$, mean value; $S D$, standard deviation.

of positive perfectionism and altruistic behavior on the association between perceived parenting styles and mental health by using structural equation models.

First, the direct effect of perceived parenting styles on mental health was investigated using a structural equation model, and the results revealed that the model fitted favorably, where $\chi^{2} / \mathrm{df}=2.790, \mathrm{CFI}=0.988, \mathrm{TLI}=0.978$, RMSEA $=0.058$. Specifically, parental rejection can directly and positively predict mental health $(\beta=0.16$, $p<0.05)$, parental emotional warmth can directly and negatively predict mental health $(\beta=-0.44, p<0.001)$, and parental overprotection cannot directly predict mental health $(\beta=0.11, p>0.05)$. Second, by considering parental rejection, emotional warmth, and overprotection as independent variables; mental health as the dependent variable; and positive perfectionism and altruistic behavior as the mediating variables; Model 1 (parental rejection $\rightarrow$ positive perfectionism $\rightarrow$ altruistic behavior $\rightarrow$ mental health; see Figure 1), Model 2 (parental emotional warmth $\rightarrow$ positive perfectionism $\rightarrow$ altruistic behavior $\rightarrow$ mental health; see Figure 2), and Model 3 (parental overprotection $\rightarrow$ positive perfectionism $\rightarrow$ altruistic behavior $\rightarrow$ mental health; see Figure 3) were established. All the mediation models exhibited accessible goodness of fit, as presented in Table 4.

This study further used the nonparametric percentile Bootstrap method to test the significance of the mediating effect. ${ }^{44}$ The mediating effect was significant if the $95 \%$ confidence interval did not include 0 . The test results (see Table 5) revealed that, for parental rejection, the mediating effects of positive perfectionism and altruistic behavior on the association between parental rejection and mental health were not significant $(95 \%$ confidence intervals were respectively $[-0.0278,0.0186]$ and $[-0.0032,0.0281])$, and the chain multiple mediating effect of positive perfectionism and altruistic behavior was also not significant $[-0.0065,0.0028]$. For parental emotional warmth, positive perfectionism and altruistic behavior exerted significant mediating effects on the association between parental emotional warmth and mental health ( $95 \%$ confidence intervals were respectively $[-0.0779$, $-0.0148]$ and $[-0.0473,-0.0015])$, and the chain multiple mediating effect of positive perfectionism and altruistic behavior was also significant $[-0.0161,-0.0011]$. For parental overprotection, the mediating effects of positive perfectionism and altruistic behavior on the association between parental overprotection and mental health were not significant $(95 \%$ confidence intervals were respectively $[-0.0543,0.0012]$ and $[-0.0148,0.0129])$, and the chain multiple mediating effect of positive perfectionism and altruistic behavior was also not significant $[-0.0135,0.0006]$.

\section{Multi-Group Analysis of Gender Differences}

To explore whether significant gender differences exist in the aforementioned mediating models, the multi-group

Table 3 Correlations Among the Key Study Variables

\begin{tabular}{|c|c|c|c|c|c|c|c|}
\hline & $\mathbf{I}$ & 2 & 3 & 4 & 5 & 6 & 7 \\
\hline I Parental rejection & - & & & & & & \\
\hline 2 Parental emotional warmth & $-0.17 * * *$ & - & & & & & \\
\hline 3 Parental overprotection & $0.78 * * *$ & $0.14 * * *$ & - & & & & \\
\hline 4 Positive perfectionism & 0.02 & $0.32 * * *$ & $0.11 * *$ & - & & & \\
\hline 5 Negative perfectionism & $0.46 * * *$ & $-0.11 * *$ & $0.43^{* * *}$ & $0.27 * * *$ & - & & \\
\hline 6 Altruistic behavior & -0.05 & $0.22 * * *$ & 0.03 & $0.26 * * *$ & -0.01 & - & \\
\hline 7 Mental health & $0.14 * * *$ & $-0.34 * * *$ & 0.08 & $-0.25 * * *$ & $0.25 * * *$ & $-0.20 * * *$ & - \\
\hline M & 1.58 & 2.89 & 2.09 & 3.82 & 3.21 & 4.08 & 1.55 \\
\hline SD & 0.66 & 0.64 & 0.52 & 0.66 & 0.73 & 0.71 & 0.41 \\
\hline
\end{tabular}

Notes: $* * p<0.01$, ***p $<0.001$.

Abbreviations: $M$, mean value; $S D$, standard deviation. 


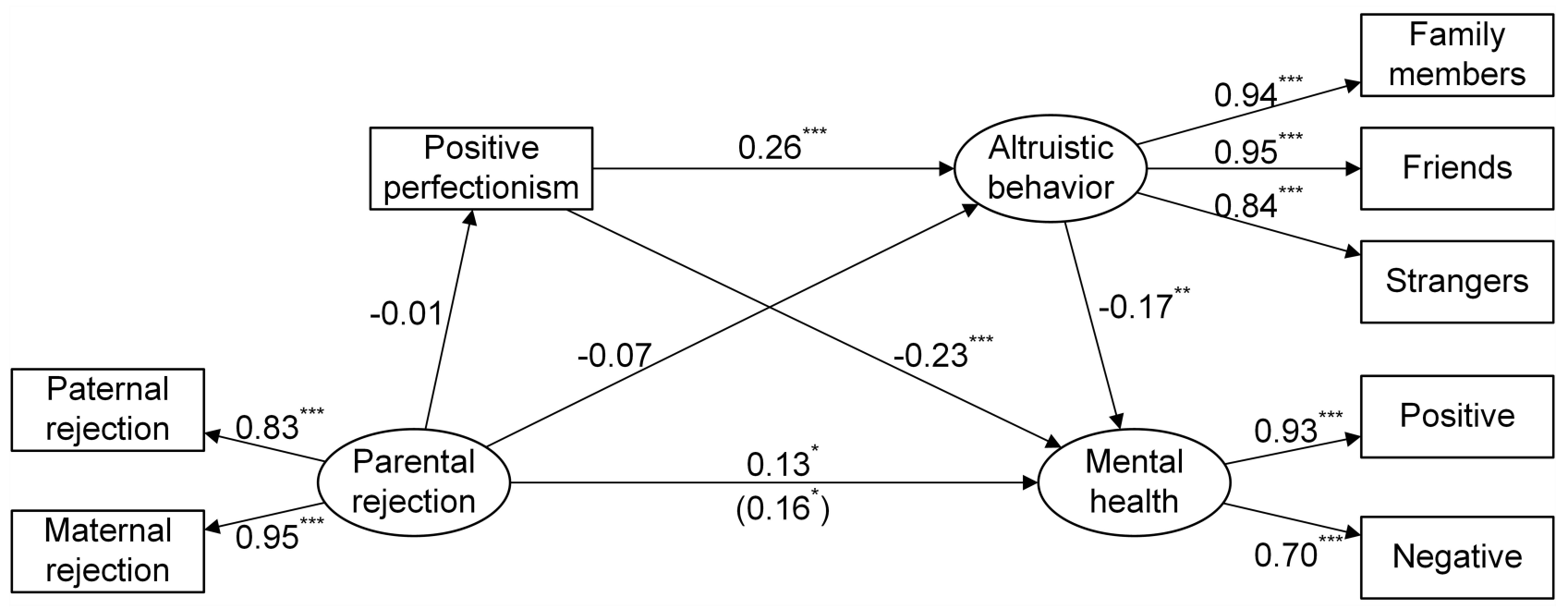

Figure I The relationships between perceived parental rejection, positive perfectionism, altruistic behavior, and mental health. Notes: $*_{p}<0.05, *_{p}<0.01, *_{*} p<0.001$.

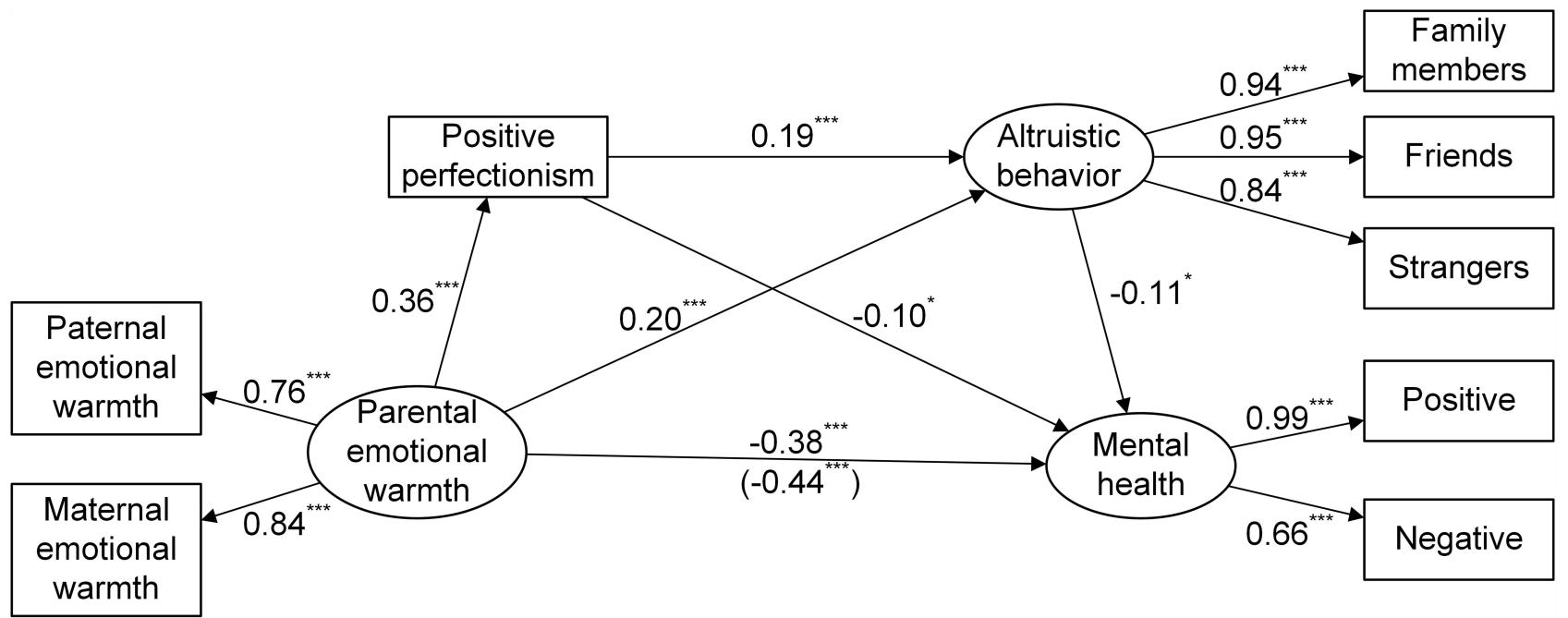

Figure 2 The relationships between perceived parental emotional warmth, positive perfectionism, altruistic behavior, and mental health. Notes: $*_{p}<0.05, * * p<0.001$.

analysis was conducted to compare the gender differences between the associations. First, this study tested the unconstrained model, allowing the free estimation of path coefficients in the men and women groups. Second, this study tested the constrained model, which constrained the specific path coefficients. Third, this study compared the unconstrained model with the constrained model. The results (see Table 6) indicated that no significant gender differences were observed between the parental rejection and emotional warmth models, which indicated gender differences were not significant in positive perfectionism and altruistic behavior between the parental rejection, emotional warmth, and mental health models. However, significant gender differences were detected in the parental overprotection model. Parental overprotection had significantly higher effect on the mental health of women $(\beta=$ $0.23, p<0.05)$ than that of men $(\beta=-0.02, p>0.05)$.

\section{Discussion}

This study examined the relationships among perceived parenting styles, positive perfectionism, altruistic behavior, and mental health in university students. The results revealed that parental rejection can positively predict mental health, emotional warmth can negatively predict mental health, and overprotection cannot effectively predict mental health. This is similar to previous research which 


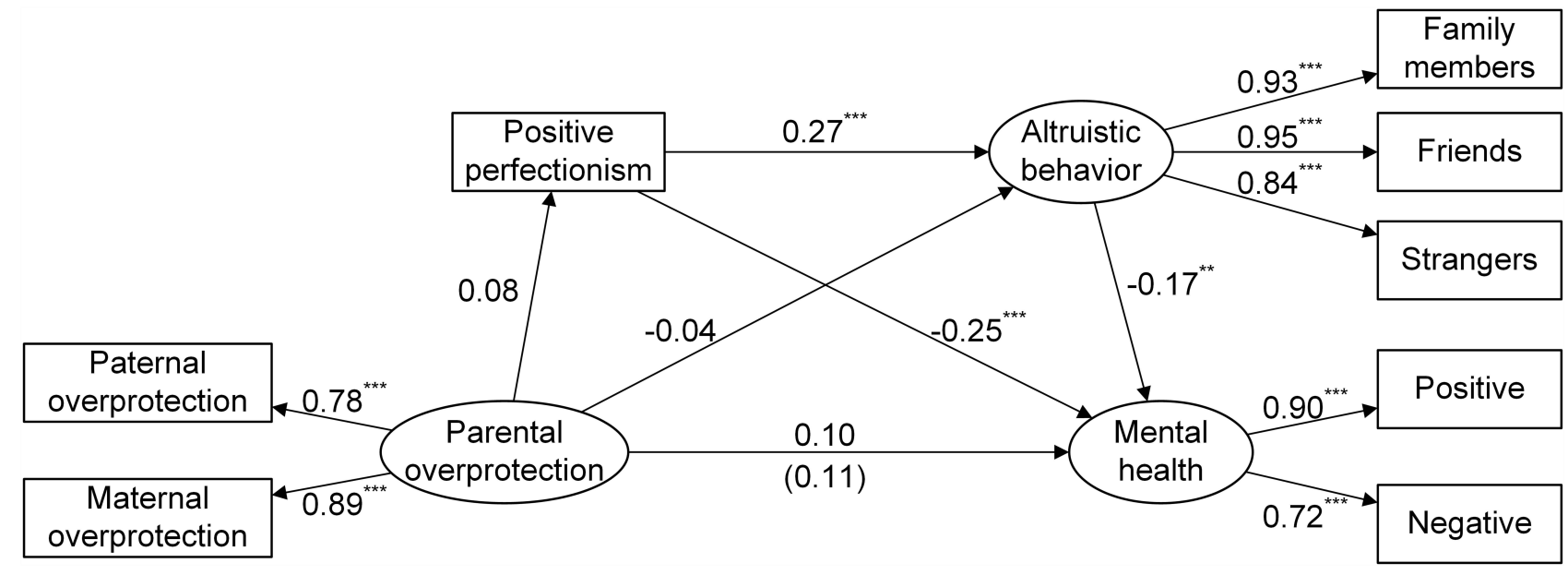

Figure 3 The relationships between perceived parental overprotection, positive perfectionism, altruistic behavior, and mental health.

Notes: ${ }^{* *} p<0.01$, ***p $<0.001$.

suggested that parental overprotection in Chinese culture may have less negative effects on children's health development, compared with that in Western cultures. ${ }^{45}$ Chinese children may have been accustomed to their parents' protection, a common parenting behavior in China, thus experience less aversions and frustrations. ${ }^{37}$

The results of the mediating effect test revealed that parental emotional warmth can affect children's mental health through the mediating role of positive perfectionism and altruistic behavior and the chain multiple mediating role of the two variables. Positive perfectionism played a mediating role in the association between parental emotional warmth and children's mental health; that is, parental emotional warmth can not only directly predict mental health but also indirectly predict mental health through positive perfectionism. This proved Hypothesis 1 and the arguments of $\mathrm{Zi}$ and $\mathrm{Zhou}$ from an empirical point of view, ${ }^{46}$ and this is also similar to conclusion of Feng who concluded that good parenting styles are conducive to children's strict demands and self-control on themselves, and the formation of positive perfectionist personality. ${ }^{47}$ Parents' rearing styles are mainly related to the adaptive dimension of perfectionism (ie, organization). This shows that people with a high degree of organization are more likely to come from families where their parents are more warm and understanding of them. On the contrary, people with a low degree of organization are more likely to come from families where their parents educate their children by means of punishment, excessive interference, excessive protection or refusal and negation. ${ }^{46}$ Children who received appropriate parental emotional warmth and care from parents were more likely to show positive perfectionism. This influence enabled the children to understand their parents better as well as enhances the children's mental health. Children growing up in a positive parenting environment adopt organized thinking to have a positive attitude when they encounter difficulties and often do not cling to their mistakes when they fail. Therefore, positive parenting styles can lead to higher positive perfectionism in children, and thus, higher mental health status. The results of this study confirmed the mediating role of positive perfectionism in the association between parental emotional warmth and mental health.

Altruistic behavior played a mediating role in the association between parental emotional warmth and children's mental health, thus confirming Hypothesis 2. Specifically, in a warm family environment, children acquire altruistic behavior according to the words and deeds of their parents.

Table 4 Goodness-of-Fit Indices for the Structural Equation Models

\begin{tabular}{|l|c|c|c|c|c|c|}
\hline & $\chi^{2}$ & df & $\chi^{2} / \mathbf{d f}$ & CFI & TLI & RMSEA \\
\hline Parental rejection model (Model I) & 41.883 & 15 & 2.792 & 0.988 & 0.978 & 0.058 \\
Parental emotional warmth model (Model 2) & 27.773 & 15 & 1.852 & 0.994 & 0.989 & 0.040 \\
Parental overprotection model (Model 3) & 37.020 & 15 & 2.468 & 0.990 & 0.981 & 0.053 \\
\hline
\end{tabular}


Table 5 Bootstrap Analysis of the Mediating Effects

\begin{tabular}{|c|c|c|c|c|}
\hline & \multirow[t]{2}{*}{ Effect } & \multirow[t]{2}{*}{ Proportion } & \multicolumn{2}{|c|}{$\begin{array}{l}\text { 95\% Confidence } \\
\text { Intervals }\end{array}$} \\
\hline & & & Lower & Upper \\
\hline Parental rejection $\rightarrow$ mental health & 0.1300 & $89.90 \%$ & 0.0330 & 0.1334 \\
\hline Parental rejection $\rightarrow$ positive perfectionism $\rightarrow$ mental health & 0.0023 & $1.59 \%$ & -0.0278 & 0.0186 \\
\hline Parental rejection $\rightarrow$ altruistic behavior $\rightarrow$ mental health & 0.0119 & $8.23 \%$ & -0.0032 & 0.0281 \\
\hline Parental rejection $\rightarrow$ positive perfectionism $\rightarrow$ altruistic behavior $\rightarrow$ mental health & 0.0004 & $0.28 \%$ & -0.0065 & 0.0028 \\
\hline Parental emotional warmth $\rightarrow$ mental health & 0.3800 & $85.30 \%$ & -0.2325 & -0.1240 \\
\hline Parental emotional warmth $\rightarrow$ positive perfectionism $\rightarrow$ mental health & 0.0360 & $8.08 \%$ & -0.0779 & -0.0148 \\
\hline Parental emotional warmth $\rightarrow$ altruistic behavior $\rightarrow$ mental health & 0.0220 & $4.94 \%$ & -0.0473 & -0.0015 \\
\hline Parental emotional warmth $\rightarrow$ positive perfectionism $\rightarrow$ altruistic behavior $\rightarrow$ mental health & 0.0075 & $1.68 \%$ & -0.0161 & -0.0011 \\
\hline Parental overprotection $\rightarrow$ mental health & 0.1100 & $78.29 \%$ & -0.0196 & 0.1484 \\
\hline Parental overprotection $\rightarrow$ positive perfectionism $\rightarrow$ mental health & 0.0200 & $14.24 \%$ & -0.0543 & 0.0012 \\
\hline Parental overprotection $\rightarrow$ altruistic behavior $\rightarrow$ mental health & 0.0068 & $4.84 \%$ & -0.0148 & 0.0129 \\
\hline Parental overprotection $\rightarrow$ positive perfectionism $\rightarrow$ altruistic behavior $\rightarrow$ mental health & 0.0037 & $2.63 \%$ & -0.0135 & 0.0006 \\
\hline
\end{tabular}

This is dissimilar to proposal of Li who proposed that children's prosocial tendency is only related to the punishment dimension of parenting. ${ }^{21}$ More warmth and tolerance from parents was conducive to driving a positive outlook about life among children. Individuals with positive emotions were more willing to act in accordance with their moods. ${ }^{48}$ Therefore, such children were more likely to shape their behaviors with an optimistic attitude, improve interpersonal relationships, and be more considerate of others in social interactions rather than being selfcentered. The development of altruistic behavior helped individuals realize their self-worth and pursue social interaction, find a sense of self-value in social interaction, and enhance their sense of happiness and satisfaction in life, which in turn promoted physical and mental health. These findings indicated that positive parenting styles were more conducive to the development of children's altruistic behavior, which in turn promoted a more favorable mental health status. Clearly, altruistic behavior was a crucial mediator of the relationship between perceived parenting styles and mental health.

Positive perfectionism and altruistic behavior also played a chain multiple mediating role in the association between parental emotional warmth and mental health. Thus, Hypothesis 3 was confirmed. The more affirmations parents provide their children, the stronger is the children's self-identity and the more confident and organized they will be in handling daily life affairs. This allows them to display altruistic behavior driven by positive and satisfying emotions and promotes their physical and mental health. In addition, this study identified that the mediating effects of negative perfectionism on the associations among perceived parenting styles, altruistic behavior, and mental health were nonsignificant. Individuals with negative perfectionism tend to pay more attention to their own characteristics according to external standards and pursue more self-development through traditional thinking, which reduces the possibility of the development of altruistic behavior among them. Compared with children who grew up with positive parenting styles, children who grew up with negative parenting styles were more likely to develop negative emotions in life, which are not conducive to achieving a healthy mental status. This is similar to proposal of Zhi who proposed that family environment is related to depressive environment, and the more negative the living environment is, the worse it is for children. ${ }^{38}$ When children's behavior or performance do not meet the high standards set by their parents, children are prone to generate negative self-cognition and display negative internalized and externalized behaviors. ${ }^{49,50}$ On the basis of relevant studies, ${ }^{8,12,28}$ this study further revealed the mechanism underlying the effect of parenting styles on mental health, elucidated the mechanism of the effects of perfectionism and altruistic behavior, and provided crucial implications for future empirical research on perfectionism and altruistic behavior. This study did not collect sufficient data to prove that positive perfectionism and altruistic behavior exert a chain multiple mediating effect on the association between parental rejection, overprotection, and mental health. This could be probably 
Table 6 Goodness-of-Fit Indices for the Multi-Group Structural Equation Models

\begin{tabular}{|c|c|c|c|c|c|c|c|c|c|}
\hline & $\chi^{2}$ & df & $\chi^{2} / \mathbf{d f}$ & CFI & TLI & RMSEA & $\Delta \mathbf{d f}$ & $\Delta \chi^{2}$ & $p$ \\
\hline \multicolumn{10}{|c|}{ Parental rejection model } \\
\hline Unconstrained & 55.007 & 30 & 1.834 & 0.989 & 0.980 & 0.040 & 6 & 6.130 & 0.409 \\
\hline Constrained & 61.137 & 36 & 1.698 & 0.989 & 0.983 & 0.037 & & & \\
\hline \multicolumn{10}{|c|}{ Parental emotional warmth model } \\
\hline Unconstrained & 49.776 & 42 & 1.659 & 0.991 & 0.983 & 0.036 & 6 & 6.332 & 0.387 \\
\hline Constrained & 56.108 & 36 & 1.559 & 0.991 & 0.986 & 0.033 & & & \\
\hline \multicolumn{10}{|c|}{ Parental overprotection model } \\
\hline Unconstrained & 54.803 & 30 & 1.827 & 0.988 & 0.978 & 0.040 & 6 & 13.572 & 0.035 \\
\hline Constrained & 68.375 & 36 & 1.899 & 0.985 & 0.976 & 0.041 & & & \\
\hline
\end{tabular}

because parental rejection and overprotection have a twoway effect on perfectionism or altruistic behavior. Parents who were excessively indifferent, strict, or doting on their children may cause the children's self-cognition to be ambiguous and even the development of reverse psychology in the children, which affects their healthy growth.

According to the analysis of gender differences, men faced higher parental rejection and overprotection than did women. This is similar to findings of Huang et al that men scored higher than women in the dimensions of paternal rejection and overprotection. ${ }^{3}$ This means that compared with women, men's parents tend to take a strict attitude towards them and have more stringent requirements. This may be because of the conventional belief among parents that boys should undergo challenges, which may have led to the parents habitually rejecting boys emotionally. Related studies have indicated that the concept "value boys over girls" is still engrained in the minds of most Chinese people, ${ }^{51,52}$ wherein they believed that boys must carry forward the family name and legacy from generation to generation. In particular, the One-Child Policy implemented in China has caused parents to pay special attention to or overpamper boys in the family. Moreover, boys are generally more rebellious and impulsive than girls in adolescence, so they are easy to irritate their parents, which may also affect their parents' parenting styles. ${ }^{3}$ In addition, the multi-group analysis of gender differences found that parental overprotection had significantly higher effect on the mental health of women (vs men), which means, women (vs men) were significantly more influenced by parental overprotection. This indicated that girls were more susceptible to parents' influence than boys in early childhood. For example, parents may be overly caring and protective when their daughters fall down, but they may often ignore their sons' fall and encourage them to continue playing, this finding is consistent with those of related studies. ${ }^{52,53}$ Parents should pay more attention to the physical and mental health development of girls.

In real life, parents should not excessively adopt negative parenting styles such as rejection and overprotection. Instead, they must respect the children and provide them plenty of room for growth. Parents should use parenting styles involving love and care and create a relaxed and warm family environment to cultivate positive perfectionism in children and encourage their altruistic behavior. ${ }^{12,20}$ Moreover, the results of this study showed that positive perfectionism can directly affect mental health or indirectly affect mental health through altruistic behavior. University students are at the crucial age when their selfconsciousness is built and their logical thinking ability is forged. At this age of the children, parents should adopt positive perfectionism to cultivate their children's thinking ability, so that they can gain a sense of self-worth and be easily motivated to implement altruistic behavior. Positive perfectionism played an essential role in the change from passive learning of altruistic behavior to active implementation of altruistic behavior. In addition, according to related studies, ${ }^{28,49}$ some other variables may influence the relationship between perfectionism and altruistic behavior, such as motivation, morality, and cognition, which can be evaluated in future research. Finally, the family and external environment must work closely together to increase the levels of positive perfectionism and altruistic behavior, such as improving communication efficiency and 
taking appropriate and positive measures to jointly enhance the mental health of university students.

\section{Limitations}

There were some limitations in this study that should be borne in mind when assessing the value of these findings. First, participants of the present study are not young people "in general", but they are university students. Thus, this aspect should be a limitation of the study in order to avoid to generalizing the results to the entire young population. Moreover, the participants in this study were relatively homogenous (from one province in Eastern China), so these findings should be treated with caution. Future research needs to replicate these findings in more representative samples. Second, the sample was composed of more women than men. A larger proportion of women participants also hinders us from applying the findings to the general population. Future studies should be conducted by recruiting a nationally representative sample. Third, the cross-sectional design in this study weakens inference about the causal relationships between perceived parenting styles and mental health. Future research needs to specify the direction of the relationships with longitudinal design that investigates the effects of perceived parenting styles on mental health or experimentally observes parenting styles to explore the resultant changes in mental health. Fourth, this study was heavily relied on self-reports, which may lead to reliance on self-awareness and reported biases, ${ }^{54}$ future research should test the effects of perceived parenting styles with more varied procedures.

\section{Conclusion}

This study found the positive effects of parental emotional warmth and the negative effects of parental rejection on university students' mental health, and the chain multiple mediation effect of university students' positive perfectionism and altruistic behavior between parental emotional warmth and university students' mental health. This study empirically supported the ecological systems theory, ${ }^{2}$ the microsystems are important during the development process because they have direct effects on immediate and proximal factors that shape human development. The theory identifies the family as a microsystem that has profound influence on development since it is the immediate environment in which individuals live. Moreover, the exploration of mediating effect of perfectionism and altruistic behavior expands and enriches the relationship mechanisms between parenting styles and children's mental health. By examining these relationship mechanisms, we also found that university students' organization could influence their own altruistic behavior. Although in this study it cannot be fully explained that the altruistic behavior of university students is entirely determined by positive perfectionism, our findings highlight the importance of positive perfectionism and altruistic behavior in the relationship between parents' rearing styles and university students' mental health. These findings provide a manual for university students to create a loving growth environment.

University students leave their parents to live alone, there is a lack of their parents' company. They communicate with their parents through instant messaging tools most of the time in their daily life. When facing the challenges of interpersonal, academic and life, they need more care from their parents to support them to face the pressure and overcome difficulties, so as to improve their mental health. It is suggested that parents should make their children feel loved, accepted and understood through various ways in their daily life. Parents should adopt more supportive ways to give their children more attention instead of blindly indulgence or control. By establishing a good object relationship, they can improve the mental health level of university students. Therefore, for Chinese parents, more emotional warmth, more support and involvement, and less rejection in parent-child interactions are encouraged. In light of these findings, this study would also suggest that specific attention should be paid to university students' positive perfectionism and altruistic behavior, which is of central importance in fostering university students' mental health development.

\section{Acknowledgments}

The authors thank all of the participants in this study and acknowledge support from the School.

\section{Author Contributions}

All authors contributed to data analysis, drafting or revising the article, gave final approval of the version to be published, and agree to be accountable for all aspects of the work. All authors have agreed on the journal to which the article will be submitted.

\section{Funding}

This research was supported by the National Social Science Fund of China (19CSH048). 


\section{Disclosure}

The authors declare no conflict of interest.

\section{References}

1. Chatterjee I, Saha D. Mental health status and quality of sleep of critical ward and general ward nurses. Indian J Health Well Being. 2018;9(6):823-828.

2. Bronfenbrenner U. Ecology of the family as a context for human development: research perspectives. Dev Psychol. 1986;22 (6):723-742. doi:10.1037/0012-1649.22.6.723

3. Huang ZW, Li YC, Chang K, et al. Relationship between college student's mental health and parenting style: the mediating effect of psychological capital. China J Health Psychol. 2020;28(5):737-742. doi:10.13342/j.cnki.cjhp.2020.05.025

4. Chen SM, Zhang Y, Lu WC. A review of the influencing factors of parenting styles. Chin J Clin Psychol. 2020;28(4):857-860. doi:10.16128/j.cnki.1005-3611.2020.04.043

5. Darling N, Steinberg L. Parenting style as context: an integrative model. Psychol Bull. 1993;113(3):487-496. doi:10.1037/00332909.113.3.487

6. Li YZ. Influence of parenting styles on learning engagement in high school students. Chin J Clin Psychol. 2018;26(5):997-1001. doi:10.16128/j.cnki.1005-3611.2018.05.034

7. Zhang JR, Meng FF, Ling H, et al. Relationship among childhood abuse, parenting styles, attachment, and antisocial personality disorder in college students. Chin J Clin Psychol. 2021;29(1):28-32. doi:10.16128/j.cnki.1005-3611.2021.01.006

8. Li BL. The family influence on the mental health of adolescents and its promotion countermeasures. J Chin Soc Educ. 2020;S1:12-13.

9. Wen $\mathrm{H}$, Ma H, Zhang CY. The relationship between parental rearing styles and mental health of college students: the mediating role of security. Chin J Health Stat. 2021;38(2):226-228. doi:10.3969/j. issn.1002-3674.2021.02.015

10. Shafran R, Mansell W. Perfectionism and psychopathology: a review of research and treatment. Clin Psychol Rev. 2001;21(6):879-906. doi:10.1016/S0272-7358(00)00072-6

11. Zi F, Zhou X. The Chinese Frost multidimensional perfectionism scale: an examination of its reliability and validity. Chin $J$ Clin Psychol. 2006;14(6):560-563. doi:10.16128/j.cnki.10053611.2006.06.003

12. Zhou XT. Research on the relationship among parenting style, college students' perfectionism and mental health. Doctoral Dissertation of Central South University. 2012.

13. Flett GL, Hewitt PL, Oliver JM, et al. Perfectionism in children and their parents: a developmental analysis. In: Flett GL, Hewitt PL, editors. Perfectionism: Theory, Research, and Treatment. Washington: American Psychological Association; 2002:89-132.

14. Wang XK, Zi F. A case study on perfectionism of college students with majoring in psychology. China $J$ Health Psychol. 2008;6:715-718. doi:10.13342/j.cnki.cjhp.2008.06.021

15. García-Villamisar D, Dattilo J, Pozo AD. Depressive mood, eating disorder symptoms, and perfectionism in female college students: a mediation analysis. Eat Disord. 2012;20(1):60-72. doi:10.1080/ 10640266.2012.635569

16. DiBartolo PM, Li CY, Frost RO. How do the dimensions of perfectionism relate to mental health? Cognit Ther Res. 2008;32 (3):401-417. doi:10.1007/s10608-007-9157-7

17. Kuang LP, He XM, Zu SM, et al. The effect of inappropriate parenting styles on self-injury: the mediating effect of perfectionism. Chin J Special Educ. 2017;11:86-91.

18. Harman O. A history of the altruism-morality debate in biology. Behaviour. 2014;151(2-3):147-165. doi:10.1163/1568539X00003133
19. Zhou ZR, Liu L. New progress in the development of children's altruistic behavior. Theory Prac Educ. 2008;28(S2):103-104.

20. Markiewicz D, Doyle AB, Brendgen M. The quality of adolescents' friendships: associations with mothers' interpersonal relationships, attachments to parents and friends, and prosocial behaviors. J Adolesc. 2001;24(4):429-445. doi:10.1006/jado.2001.0374

21. Li D. Research on the factors influencing children's prosocial behavior. Psychol Sci. 2000;23(3):285-288. doi:10.16719/j.cnki.16716981.2000.03.007

22. Rubin KH, Bukowski WM, Parker JG. Peer interactions, relationships and groups. In: Damon W, Eisenberg N, editors. Handbook of Child Psychology. New York: Wiley; 1998:619-700.

23. Gerardy H, Mounts NS, Luckner AE, et al. Mothers' management of adolescent peer relationships: associations with aggressive, prosocial, and playful behavior. $J$ Genet Psychol. 2015;176(5):299-314. doi:10.1080/00221325.2015.1066746

24. Kou Y, Ma Y, Tan C. Chinese college students' prosocial tendencies, prosocial moral reasoning and their correlation patterns. Psychol Sci. 2004;27(2):329-332. doi:10.16719/j.cnki.16716981.2004.02.022

25. Berkowitz L. Social norms, feelings, and other factors affecting helping and altruism. Adv Exp Soc Psychol. 1972;6:63-108. doi:10.1016/ S0065-2601(08)60025-8

26. Adler A. Mass psychology. Int J Individ Psychol. 1937;2(2):111-120.

27. Guo QK, Feng LL. Why good things happen to good people: the mechanisms that altruistic behaviors reward the actors. QILU J. 2016;5:99-105. doi:10.3969/j.issn.1001-022X.2016.05.018

28. Zhang LG, Zhang L, Kou Y, et al. The characteristics of perfectionism and its relationship with prosocial tendencies. Psycholog Dev Educ. 2011;27(4):365-373. doi:10.16187/j.cnki.issn10014918.2011.04.009

29. Carlo G, Hausmann A, Christiansen S, et al. Sociocognitive and behavioral correlates of a measure of prosocial tendencies for adolescents. J Early Adolesc. 2003;23(1):107-134. doi:10.1177/ 0272431602239132

30. Chen Y, Zhu L, Chen Z, Botbol M. Family income affects children's altruistic behavior in the dictator game. PLoS One. 2013;8:e80419. doi:10.1371/journal.pone.0080419

31. Cameron L, Erkal N, Gangadharan L, et al. Little emperors: behavioral impacts of china's one-child policy. Science. 2013;339 (6122):953-957. doi:10.1126/science.1230221

32. Li J, Zhu L, Gummerum M, et al. The development of social value orientation across different contexts. Int J Psychol. 2013;48:469-480. doi:10.1080/00207594.2012.673725

33. Chao RK. Beyond parental control and authoritarian parenting style: understanding Chinese parenting through the cultural notion of training. Child Dev. 1994;65:1111-1119. doi:10.2307/1131308

34. Feng LL, Guo QK. Beneficial effect of altruism on well-being among Chinese college students: the role of self-esteem and family socioeconomic status. J Soc Serv Res. 2017;43(3):416-431. doi:10.1080/ 01488376.2016.1242449

35. Liu L, Wang M. Parental harsh discipline and adolescent problem behavior in china: perceived normativeness as a moderator. Child Abuse Negl. 2018;86:1-9. doi:10.1016/j.chiabu.2018.09.009

36. Faul F, Erdfelder E, Lang AG, et al. G*Power 3: a flexible statistical power analysis program for the social, behavioral, and biomedical sciences. Behav Res Methods. 2007;39:175-191. doi:10.3758/ bf03193146

37. Jiang J, Lu ZR, Jiang BJ, et al. Revision of the short-form Egna Minnen Beträffande Uppfostran for Chinese. Psycholog Dev Educ. 2010;1:94-99. doi:10.16187/j.cnki.issn1001-4918.2010.01.017

38. Zhi FY, Yang XZ, Yin CY. The effect of parenting styles on middle school students' cyberbullying: the mediating role of depression. J Guizhou Normal Univ. 2018;36(6):115-119. doi:10.16614/j.gznuj. zrb.2018.06.019 
39. Wu P, Ma SN, Fang ZQ, et al. The latent classes of parenting style: an application of latent profile analysis. Stud Psychol Behav. 2016;14 (4):523-530

40. Li YM, Li YX. The factor structure of the 12-item general health questionnaire: the multi-group analyses. Psycholog Explor. 2015;35 (4):355-359. doi:10.3969/j.issn.1003-5184.2015.04.012

41. Kline RB. Principles and Practice of Structural Equation Modeling. 2nd ed. New York: Guilford Press; 2005.

42. McDonald RP, Ho MR. Principles and practice in reporting structural equation analyses. Psychol Methods. 2002;7(1):64-82. doi:10.1037/ 1082-989X.7.1.64

43. Preacher KJ, Hayes AF. Asymptotic and resampling strategies for assessing and comparing indirect effects in multiple mediator models. Behav Res Methods. 2008;40(3):879-891. doi:10.3758/ BRM.40.3.879

44. Hayes AF. Introduction to Mediation, Moderation, and Conditional Process Analysis: A Regression-Based Approach. New York: Guilford Press; 2013.

45. Fosse GK, Holen A. Childhood environment of adult psychiatric outpatients in Norway having been bullied in school. Child Abuse Negl. 2002;26:129-137. doi:10.1016/S0145-2134(01)00312-X

46. Zi F, Zhou X. The relationship between students' perfectionism and parental rearing behavior. China $J$ Health Psychol. 2005;13 (5):321-323. doi:10.3969/j.issn.1005-1252.2005.05.001

47. Feng H. Research on correlation between college students' positive perfectionism and parent rearing style. China J Health Psychol. 2010;18(8):982-983. doi:10.13342/j.cnki.cjhp.2010.08.049
48. Wegener DT, Petty RE. Mood management across affective states: the hedonic contingency hypothesis. J Pers Soc Psychol. 1994;66 (6):1034-1048. doi:10.1037/0022-3514.66.6.1034

49. Fei DZ, Ma YM. Is perfectionism really perfect? — A review on perfectionism. Chin J Clin Psychol. 2017;25(3):566-571. doi:10.16128/j.cnki.1005-3611.2017.03.039

50. Soenens B, Luyckx K, Vansteenkiste M, et al. Maladaptive perfectionism as an intervening variable between psychological control and adolescent depressive symptoms: a three-wave longitudinal study. $J \quad$ Fam Psychol. 2008;22(3):465-474. doi:10.1037/08933200.22.3.465

51. Liao LP, Zhang CL. Does the son preference harm girls' health? Evidence from China family panel studies. Econ Rev. 2020;2:139-154. doi:10.19361/j.er.2020.02.09

52. Sun XD, Lai KS. Are mothers with sons more traditional? — The influence of sons and daughters on parents' gender ideology. Sociolog Stud. 2016;31(2):194-216+245. doi:10.19934/j.cnki. shxyj.2016.02.010

53. Graham RA, Weems CF. Identifying moderators of the link between parent and child anxiety sensitivity: the roles of gender, positive parenting, and corporal punishment. J Abnorm Child Psychol. 2015;43(5):885-893. doi:10.1007/s10802-014-9945-y

54. Stone AA, Turkkan JS, Bachrach CA, et al. The Science of SelfReport: Implications for Research and Practice. Mahwah, NJ: Erlbaum; 1999.
Psychology Research and Behavior Management

\section{Publish your work in this journal}

Psychology Research and Behavior Management is an international, peer-reviewed, open access journal focusing on the science of psychology and its application in behavior management to develop improved outcomes in the clinical, educational, sports and business arenas. Specific topics covered in the journal include: Neuroscience, memory and decision making; Behavior modification and management; Clinical

\section{Dovepress}

applications; Business and sports performance management; Social and developmental studies; Animal studies. The manuscript management system is completely online and includes a very quick and fair peer-review system, which is all easy to use. Visit http://www. dovepress.com/testimonials.php to read real quotes from published authors. 